California GAMA Special Study: Analysis of Carbamazepine, Oxcarbazepine and Metabolites as Wastewater Tracers in Water Resource Studies

J. E. Owens, A. K. Vu, B. K. Esser

August 20, 2010 
This document was prepared as an account of work sponsored by an agency of the United States government. Neither the United States government nor Lawrence Livermore National Security, LLC, nor any of their employees makes any warranty, expressed or implied, or assumes any legal liability or responsibility for the accuracy, completeness, or usefulness of any information, apparatus, product, or process disclosed, or represents that its use would not infringe privately owned rights. Reference herein to any specific commercial product, process, or service by trade name, trademark, manufacturer, or otherwise does not necessarily constitute or imply its endorsement, recommendation, or favoring by the United States government or Lawrence Livermore National Security, LLC. The views and opinions of authors expressed herein do not necessarily state or reflect those of the United States government or Lawrence Livermore National Security, LLC, and shall not be used for advertising or product endorsement purposes.

This work performed under the auspices of the U.S. Department of Energy by Lawrence Livermore National Laboratory under Contract DE-AC52-07NA27344. 


\section{GAMA: AMBIENT GROUNDWATER Monitoring \& Assessment Program SPECIAL STUDY}

\section{California GAMA Special Study:}

Analysis of Carbamazepine, Oxcarbazepine and Metabolites as Wastewater Tracers in Water Resource Studies

Janel E. Owens*, Alexander K. Vu, and Bradley K. Esser

Lawrence Livermore National Laboratory

*Current address: University of Colorado at Colorado Springs

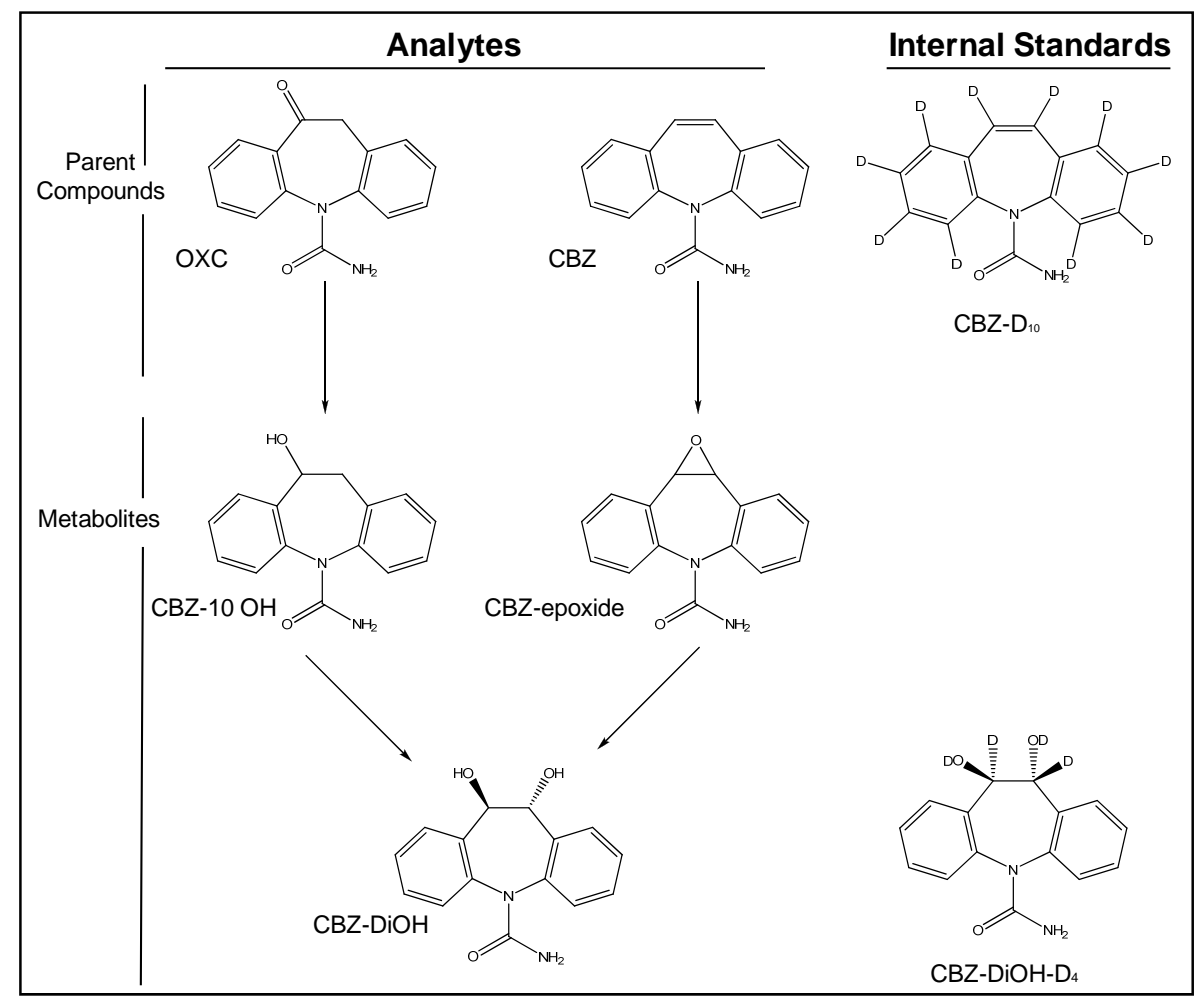

Revised Draft Final Report for GAMA Special Studies Tasks 7.4 and 10.4 LLNL-TR-450502

Prepared in cooperation with the California

State Water Resource Control Board

August 2010 
Suggested citation:

Janel E. Owens, Alexander K. Vu, and Bradley K. Esser (2010) California GAMA Special Study: Analysis of Carbamazepine, Oxcarbazepine and Metabolites as Wastewater Tracers in Water Resource Studies. Lawrence Livermore National Laboratory UCRL-TR-450502, 36 pages. 


\title{
California GAMA Special Study: Analysis of Carbamazepine, Oxcarbazepine and Metabolites as Wastewater Tracers in Water Resource Studies
}

\author{
Janel E. Owens*, Alexander K. Vu, and Bradley K. Esser \\ Lawrence Livermore National Laboratory \\ *Current address: University of Colorado at Colorado Springs
}

\section{Executive Summary}

The Groundwater Ambient Monitoring and Assessment (GAMA) Program is a comprehensive groundwater quality monitoring program managed by the California State Water Resources Control Board (SWRCB). The GAMA Special Studies project provides analyses and interpretation of constituents of concern that allow assessment of current groundwater conditions. In addition, the Special Studies project develops analyses that will enhance the monitoring and assessment effort by focusing on specific constituents of concern and water quality parameters, such as disinfection byproducts (DBP), wastewater indicators, and redox conditions, as it relates to irrigation and groundwater management.

Wastewater indicators, i.e. chemical compounds that can be used to trace effluent from wastewater treatment plants or septic systems, are of considerable value for water management. Monitoring the fate and transport of these chemical tracers in WWTP effluents, surface waters, and groundwater can aid in the assessment of the degree of chemical contamination of water resources from various industrial, domestic, or husbandry sources. Such chemical tracers must be source-specific, appreciably soluble in water, and relatively resistant to biotic or abiotic degradation, including forced degradation during processes at a WWTP. The anti-epileptic/anticonvulsant drugs carbamazepine $(5 \mathrm{H}$-dibenz $[\mathrm{b}, \mathrm{f}]$ azepine-5-carboxamide) and oxcarbazepine (10,11-dihydro-10-oxo-5H-dibenz[b,f]azepine-5-carboxamide) are thought to be good potential tracers owing to satisfaction of such requirements (Leclercq et al., 2009).

Carbamazepine (CBZ; approved in 1974) and oxcarbazepine (OXC; approved in 2000) have become some of the most widely prescribed drugs for the treatment of epilepsy, trigeminal neuralgia, and bipolar disorder. In a study of pharmaceuticals in WWTP of Finland, CBZ was determined to be one of the most heavily used drugs, with a per capita consumption rate of 2.4 $\mathrm{mg}$ /day. It has been one of the more frequently identified pharmaceuticals in WWTP effluents and river water. Additionally, CBZ was one of eleven compounds most frequently detected in a survey study of 51 compounds in source water (found in $79 \%$ of samples), finished drinking water (44\% of samples), and distribution system water ( $40 \%$ of samples) sampled from 19 U.S. facilities that provide water service for 28 million people.

Urinary metabolites of pharmaceuticals may also be good tracers of wastewater. Metabolism of CBZ, for example, is sufficiently efficient that only $1 \%$ of ingested CBZ is excreted unchanged in the urine. The primary urinary metabolites of $\mathrm{CBZ}$ are carbamazepine-epoxide (CBZ-E) and 10,11-dihydro-10,11-dihydroxycarbamazepine (CBZ-DiOH). The primary urinary metabolites of 
OXC are 10,11-dihydro-10-hydroxycarbamazepine (CBZ-10-OH) and CBZ-DiOH. The CBZ$\mathrm{DiOH}$ metabolite has been found in wastewater effluent and environmental samples at higher concentrations than the parent compounds. These parent drugs and their major metabolites may serve as useful tracers for municipal wastewaters and effluent impact on water resources given the pharmaceuticals' long use, high rate of consumption, and stability to both biotic and abiotic degradation processes.

This study developed a robust analytical method for the quantitation of $\mathrm{CBZ}, \mathrm{OXC}, \mathrm{CBZ}-\mathrm{E}$, CBZ-DiOH, and CBZ-10-OH in wastewater treatement plant (WWTP) effluent and in groundwater in the parts per trillion range. The method uses commercially available solid-phase extraction (SPE) cartridges and liquid chromatography tandem mass spectrometry (LC/MS/MS), with quantitation from a labeled internal standard. The limit of quantitation ranged from 0.01 to $0.1 \mathrm{ng}$ on-column. Surveyed water samples included WWTP primary, secondary, and tertiary treatment samples. Concentrations of metabolites in effluent are detailed here for the first time for U.S.-based WWTP.

While such work as been reported before by other groups, the work presented here is novel for using an isotopically-labeled internal CBZ standard for quantitation and compensation for matrix effects as well as providing data for CBZ, OXC and metabolite concentrations at a U.S.-based WWTP. As discussed, quantitation of CBZ, OXC and the various metabolites as novel wastewater tracers may allow for the estimation of the contamination of surveyed subsurface water sites by domestic sources.

The main body of the report consists of a manuscript being prepared for publication in a peerreviewed journal, and a protocol for sample preparation and analysis of wastewater and groundwater samples for determination of CBZ, OXC and their metabolites by SPE-LC/MS/MS.

Owens J. E., Vu A. K., and Esser B. K. (2010) Use of Carbamazepine, Oxcarbazepine and Metabolites as Novel Wastewater Tracers in Assessment of Contamination of Water Resources, in prep.

Appendix A: Protocol for the Extraction, Clean-Up, and Analysis of Carbamazepine and Related Metabolites from Collected Water Samples by Solid Phase Extraction with Analysis by LC/MS/MS 

-+Use of Carbamazepine, Oxcarbazepine and Metabolites as Novel Wastewater Tracers in the Assessment of Contamination of Water Resources
Janel E. Owens ${ }^{1,3}$, Alexander K. Vu ${ }^{1}$, and Bradley K. Esser ${ }^{2 *}$
${ }^{1}$ Forensic Science Center and ${ }^{2}$ Chemical Biology and Nuclear Science Division, Lawrence
Livermore National Laboratory, 7000 East Ave., L-231
Livermore, CA 94550
* Corresponding author: (925) 422-5247 (phone); e-mail: bkesser@1lnl.gov
${ }^{3}$ Current address: Department of Chemistry, University of Colorado at Colorado Springs, 1420
Austin Bluffs Parkway, Colorado Springs 80918

\begin{abstract}
Pharmaceuticals in the environment have attracted significant attention in recent years. The method here details the analysis of carbamazepine (CBZ), oxcarbazepine (OXC) and metabolites carbamazepine-epoxide (CBZ-epoxide), 10,11-dihydro-10-hydroxycarbamazepine (CBZ-10$\mathrm{OH})$, and 10,11-dihydro-10,11-hydroxycarbamazepine (CBZ-DiOH), from sampling sites within a wastewater treatment plant (WWTP). Samples $(500 \mathrm{~mL})$ were prepared using Oasis HLB solid phase extraction cartridges and analyzed by liquid chromatography tandem mass spectrometry and quantified using an internal standard $\left(\mathrm{CBZ}-\mathrm{D}_{10}\right)$. The limit of quantitation ranged from 0.01 to $0.1 \mathrm{ng}$ on-column. Composite samples were fortified with a mix of parent pharmaceuticals and metabolites for method validation. Reasonable recoveries were assessed for CBZ, CBZ-epoxide, and CBZ-10-OH, and CBZ-DiOH (> 70\%) and low recoveries (44\%) for OXC were observed. Concentrations of metabolites in effluent are detailed here for the first time for U.S.-based WWTP.
\end{abstract}

Keywords: carbamazepine, oxcarbazepine, metabolites, liquid chromatography, mass spectrometry 


\section{INTRODUCTION}

Chemical compounds that can be used to trace effluent from wastewater treatment plants (WWTPs) are of considerable value for management of water resources. Monitoring the fate and transport of these chemical tracers in WWTP effluents, surface waters, and groundwater can aid in the assessment of the degree of chemical contamination of water resources from various industrial, domestic, or husbandry sources. Such chemical tracers must be source-specific, appreciably soluble in water, and relatively resistant to biotic or abiotic degradation, including forced degradation during processes at a WWTP. The anti-epileptic/anti-convulsant drugs carbamazepine (5H-dibenz[b,f]azepine-5-carboxamide) and oxcarbazepine (10,11-dihydro-10oxo-5H-dibenz[b,f]azepine-5-carboxamide) are thought to be good potential tracers owing to satisfaction of such requirements (Leclercq et al., 2009).

Carbamazepine (CBZ; approved in 1974) and oxcarbazepine (OXC; approved in 2000) have become some of the most widely prescribed drugs for the treatment of epilepsy, trigeminal neuralgia, and bipolar disorder. In a study of pharmaceuticals in WWTP of Finland, CBZ was determined to be one of the most heavily used drugs, with a per capita consumption rate of 2.4 $\mathrm{mg}$ /day (Vieno et al., 2007). It has been one of the more frequently identified pharmaceuticals in WWTP effluents and river water (Gagne et al., 2006; Miao and Metcalfe, 2003; Miao et al., 2005) and recent work aimed at elucidating the ecotoxicological effects of CBZ exposure on non-human organisms (Martin-Diaz et al., 2009). Additionally, CBZ was one of eleven compounds most frequently detected in a survey study of 51 compounds in source water (found in $79 \%$ of samples), finished drinking water ( $44 \%$ of samples), and distribution system water ( $40 \%$ of samples) sampled from 19 U.S. facilities that provide water service for 28 million people (Benotti et al., 2009). These parent drugs and their major metabolites (Figure 1), which 
include carbamazepine-epoxide (CBZ-epoxide), 10,11-dihydro-10-hydroxycarbamazepine (CBZ-10-OH), and 10,11-dihydro-10,11-hydroxycarbamazepine (CBZ-DiOH) (Kupferberg, 1982), may serve as useful tracers for municipal wastewaters and effluent impact on water resources given the pharmaceuticals' long use, high rate of consumption, and stability to both biotic and abiotic degradation processes.

CBZ and its diol metabolites are unstable during analysis by GC (Baker et al., 1973; von Unruh and Paar, 1986) and derivatization techniques are occasionally employed to increase analyte stability (von Unruh and Paar, 1986). CBZ, OXC, and metabolites are now frequently analyzed using liquid chromatography with detection by mass spectrometry or tandem mass spectrometry (LC/MS or LC/MS/MS) for various matrices, including urine (Maggs et al., 1997), plasma (Breton et al., 2005; Corso et al., 2007; Maia et al., 2007) aqueous (Leclercq et al., 2009; Miao and Metcalfe, 2003) and bio-solid (Miao et al., 2005) samples. Various clean-up and extraction techniques have been employed, including liquid-liquid extraction using diethyl ethermethylene chloride (Maia et al., 2007), pressurized liquid extraction (Miao et al., 2005), on-line solid phase extraction (Trenholm et al., 2009) or solid phase extraction (SPE) with C8 phases (Corso et al., 2007) or Oasis HLB phases (Benotti et al., 2009; Leclercq et al., 2009; Miao and Metcalfe, 2003; Vanderford et al., 2003). Reported limits of detection (LOD) and limits of quantitation (LOQ) for these various matrices with LC/MS/MS analysis ranged from $0.4 \mathrm{ng} / \mathrm{L}$ (Miao and Metcalfe, 2003) to $500 \mathrm{ng} / \mathrm{L}$ (Breton et al., 2005) for CBZ, $20 \mathrm{ng} / \mathrm{L}$ (Maia et al., 2007) to $400 \mathrm{ng} / \mathrm{L}$ for OXC (Breton et al., 2005), and 0.1 ng/L (Miao and Metcalfe, 2003) to $300 \mathrm{ng} / \mathrm{L}$ for the metabolites (Breton et al., 2005).

The purpose of the work presented here was to develop and optimize an SPE method for the extraction of CBZ, OXC, and major metabolites, CBZ-epoxide, CBZ-10-OH and CBZ-DiOH 
(Figure 1), from various sampled waters followed with analysis by LC/MS/MS at part-pertrillion (ng/L) levels. These surveyed water samples included WWTP primary, secondary, and tertiary treatment samples. While such work as been reported before by other groups (Kinney et al., 2006; Leclercq et al., 2009; Miao and Metcalfe, 2003; Miao et al., 2005; Trenholm et al., 2009), the work presented here is novel for using an isotopically-labeled internal CBZ standard for quantitation and compensation for matrix effects as well as providing data for CBZ, OXC and metabolite concentrations at a U.S.-based WWTP. As discussed, quantitation of CBZ, OXC and the various metabolites as novel wastewater tracers may allow for the estimation of the contamination of surveyed subsurface water sites by domestic sources.

\section{MATERIALS AND METHODS}

\section{Units}

Concentrations are expressed as parts per million (micrograms per milliliter or $\mu \mathrm{g} / \mathrm{mL}$ ) for primary standards; parts per billion (nanograms/milliliter or $\mathrm{ng} / \mathrm{mL}$ ) for secondary standards and for spiked samples; and as parts per trillion (nanograms/liter or ng/L) for un-spiked samples.

\section{Chemicals and Reagents}

CBZ and CBZ-epoxide were purchased from Sigma-Aldrich (St. Louis, MO) at a minimum of $98 \%$ purity. A ClinCal calibrator containing CBZ-DiOH (3600 ng/mL), CBZ-10-OH (27800 ng/mL) CBZ-epoxide (5600 ng/mL), OXC (20800 ng/mL), and CBZ (11000 ng/mL) was purchased from Recipe Chemicals + Instruments GmbH (Munich, Germany). The internal standard (IS) CBZ-D ${ }_{10}(>98 \%$ purity) was from Cambridge Isotope Laboratories at a 
concentration of $100 \mu \mathrm{g} / \mathrm{mL}$ in acetonitrile. HPLC-grade water (18 M $\Omega$ ) was prepared using a Barnstead Nanopure filtration system. HPLC-grade solvents including methanol, acetonitrile, and ethyl acetate were from Fisher Scientific, as were all other chemicals unless specified otherwise.

\section{Standard Preparation}

Preparation of Internal Standard

The IS CBZ-D ${ }_{10}$ was purchased at a concentration of $100 \mu \mathrm{g} / \mathrm{mL}$ in acetonitrile. Fifty $\mu \mathrm{L}$ was dissolved in methanol to prepare $5 \mathrm{~mL}$ at $1 \mu \mathrm{g} / \mathrm{mL}$. Ten $\mu \mathrm{L}$ was added to every water sample prior to extraction and clean-up by SPE.

Standards for the Optimization of SPE Protocol

CBZ from Sigma-Aldrich was prepared by weighing out approximately $30 \mathrm{mg}$ and dissolving in $25 \mathrm{~mL}$ methanol to prepare a stock solution of $1195.2 \mu \mathrm{g} / \mathrm{mL}$. CBZ-epoxide was prepared by dissolving approximately $3 \mathrm{mg}$ in $25 \mathrm{~mL}$ methanol for a stock solution concentration of 105.8 $\mu \mathrm{g} / \mathrm{mL}$. Using these stock solutions, a working stock solution $I$ in methanol was prepared that contained CBZ and CBZ-epoxide at a concentration of 10,000 ng/mL. Using the working stock solution $I$, calibration standards were prepared in methanol ranging from $0.5 \mathrm{ng} / \mathrm{mL}$ to 1,000 $\mathrm{ng} / \mathrm{mL}$.

Standards for Method Verification Procedures and Sampled Water Analyses

The ClinCal standard was reconstituted with $3 \mathrm{~mL}$ HPLC-grade water and $600 \mu \mathrm{L}$ aliquots were pipetted into multiple amber glass autosampler vials to avoid multiple freeze/thaw cycles. Standards were prepared in HPLC-grade water ranging from $0.18 \mathrm{ng} / \mathrm{mL}$ to $2,780 \mathrm{ng} / \mathrm{mL}$, with 
specific concentrations for each analyte shown in Table 1. Ten $\mu \mathrm{L}$ of IS was added to each standard for a total final volume of $1 \mathrm{~mL}$. When not in use, standards were stored at $4{ }^{\circ} \mathrm{C}$.

\section{Instrumental Conditions}

A Waters Alliance HT 2795 liquid chromatograph with a Waters Micromass Quattro Micro api triple quadrupole mass spectrometer (Waters Corporation, Milford, MA) was used for analysis. The mass spectrometer was first calibrated using a solution of sodium iodide/cesium iodide (both purchased from Sigma-Aldrich) per manufacturer's specifications. Tune parameters for CBZ, CBZ-epoxide and IS (Table 2) were established by infusing an approximate $50 \mu \mathrm{g} / \mathrm{mL}$ solution of each prepared in methanol/water $(50 / 50, \mathrm{v} / \mathrm{v})$ containing $0.1 \%$ formic acid at 20 $\mu \mathrm{L} / \mathrm{min}$. A diluted volume of the ClinCal standard was infused to check masses and product ions of additional analytes $\mathrm{OXC}, \mathrm{CBZ}-\mathrm{DiOH}$, and $\mathrm{CBZ}-10-\mathrm{OH}$. Settings were: capillary at $3.0 \mathrm{kV}$ (positive ion mode), cone voltages were variable (Table 2), extractor at $2 \mathrm{~V}$, RF lens at $0.2 \mathrm{~V}$, source temperature at $120{ }^{\circ} \mathrm{C}$, desolvation temperature at $300{ }^{\circ} \mathrm{C}$, desolvation gas flow at 500 $\mathrm{L} / \mathrm{h}$, cone gas flow at $45 \mathrm{~L} / \mathrm{h}$, low mass and high mass resolution at 14.5 , ion energy 1 at 0.5 , entrance energy at $-1 \mathrm{eV}$, collision energies were variable (Table 2), exit energy at $2 \mathrm{eV}$, low mass and high mass resolution 2 at 15.0, ion energy 2 at 1.5, and multiplier was set to 650 arbitrary units. The dwell time was $0.1 \mathrm{~ms}$, inter-channel delay was $0.1 \mathrm{~s}$, inter-scan delay was $0.1 \mathrm{~s}$, repeats at 1 , and the span set to $0 \mathrm{Da}$. All analytes and IS were analyzed using multiple reaction monitoring (MRM) and the transitions listed in Table 2 were monitored.

The Waters 2795 HPLC consisted of a quaternary pump, in-line mobile phase degasser, temperature-controlled autosampler (maintained at $15^{\circ} \mathrm{C}$ ) and column compartment (maintained at $30{ }^{\circ} \mathrm{C}$ ). Twenty $\mu \mathrm{L}$ of standard mix or prepared sample was injected onto a $150 \times 2.1 \mathrm{~mm}$ i.d., 
$3.5 \mu \mathrm{m}$ particle XBridge C18 analytical column (Waters Corp.). Mobile phase A was water + $0.1 \%$ formic acid and mobile phase B was acetonitrile $+0.1 \%$ formic acid. The gradient program was as follows: at $0 \mathrm{~min}, 80 \% \mathrm{~A}$ (hold for $2 \mathrm{~min}$ ) to $20 \% \mathrm{~A}$ at $8 \mathrm{~min}$ (hold for $2 \mathrm{~min}$ ) returning to $80 \% \mathrm{~A}$ at $11 \mathrm{~min}$ (hold for $4 \mathrm{~min}$ ) for a total run time of $15 \mathrm{~min}$. The column was equilibrated for two minutes between samples. A constant flow rate of $0.2 \mathrm{~mL} / \mathrm{min}$ was maintained throughout. CBZ-DiOH eluted at $5.35 \mathrm{~min}, \mathrm{CBZ}-10-\mathrm{OH}$ at $7.04 \mathrm{~min}, \mathrm{CBZ}-$ epoxide at $7.94 \mathrm{~min}, \mathrm{OXC}$ at 8.28 min, and $\mathrm{CBZ}$ and $\mathrm{CBZ}-\mathrm{D}_{10}$ at $9.02 \mathrm{~min}$ (Figure 2).

Quantitation was by quadratic regression with $1 / x$ weighting with $\mathrm{n} \geq 2$ measurements per standard. A standard curve was prepared at the beginning of each sequence run and individual standards were included throughout the sequence list after every six matrix samples. The responses of these the check calibration standards were also included in the standard curve preparation. Example chromatograms of a standard at Level 6, water blank, and water sample are shown (Figure 2).

\section{Sampling}

Samples were collected in triplicate at three sampling stations within the Livermore Water Reclamation Plant (LWRP) located in Livermore, CA. Samples were collected of primary (at sedimentation tanks), secondary (post-chlorination), and tertiary (post-UV) effluent. At each sampling site, unfiltered samples were collected into two 1-L pre-cleaned I-CHEM (ThermoFisher Scientific, Rockwood, TN) amber glass bottles and one 1-L I-CHEM HDPE bottle. All samples were put on ice immediately after collection. Large-volume samples are stored in the refrigerator $\left(4^{\circ} \mathrm{C}\right)$ until sample preparation for LC/MS/MS analysis. Samples were prepared for analysis within 48 hours after sample collection. 


\section{Water Sample Preparation by Solid Phase Extraction}

Five hundred $\mathrm{mL}$ of the collected water samples were prepared for LC/MS/MS analysis using Oasis HLB columns ( $150 \mathrm{mg} / 6 \mathrm{cc}$; Waters Corp.). Ten $\mu \mathrm{L}$ of IS was added to the $500 \mathrm{~mL}$ of water sample prior to clean-up and extraction by SPE. The columns were conditioned with two column volumes of methanol followed by two column volumes of HPLC-grade water. The collected water samples were applied to the conditioned columns using a peristaltic pump such that the flow rate was $0.6 \mathrm{~mL} / \mathrm{min}$, for an approximate loading time of 14 hours. The columns were washed with $2 \mathrm{~mL}$ HPLC-grade water and eluted with $0.5 \mathrm{~mL}$ methanol followed by 0.5 $\mathrm{mL}$ ethyl acetate. Two hundred $\mu \mathrm{L}$ were transferred to a secondary vial and evaporated to near dryness using ultra-pure nitrogen. The samples were re-constituted in $75 \mu \mathrm{L}$ HPLC-grade water and transferred to a PolySpring $100 \mu \mathrm{L}$ insert. The samples were stored at $4{ }^{\circ} \mathrm{C}$ until analysis.

\section{Method Verification}

A composite matrix consisting of equal parts volume of sampled water collected at the three sampling locations at the LWRP was used for method verification studies. Three $125 \mathrm{~mL}$ aliquots of the composite matrix were each spiked with $25 \mu \mathrm{L}$ of the Level 1 calibration standard that did not contain IS. A second sample set was not spiked and served as a control group. Additionally, $10 \mu \mathrm{L}$ of the IS mix containing CBZ- $\mathrm{D}_{10}$ was added to samples in both sets. The spiked and control sample sets were then prepared for analysis using the optimized solid phase extraction protocol described above. The samples were stored at $4{ }^{\circ} \mathrm{C}$ until analysis. 


\section{Holding Time Study}

Six aliquots of $125 \mathrm{~mL}$ were taken of the effluents from each of the three sampling stations $(\mathrm{n}=18)$ and subsequently spiked with $100 \mu \mathrm{L}$ of the Level 1 calibration standard (did not contain IS). All samples were mixed well and one set of three samples from each study area was prepared by SPE and LC/MS/MS analysis as described immediately after mixing. The second set of three spiked samples from each sampling area was stored at $4^{\circ} \mathrm{C}$ for one week prior to sample preparation and analysis by LC/MS/MS as described above.

\section{Statistical Analyses}

All statistical analyses were completed using Analysis ToolPak from Microsoft Excel. Such analyses included a two-tailed Student's $t$-test assuming equal variances and single-factor analysis of variance (ANOVA).

\section{RESULTS AND DISCUSSION}

\section{Method Characteristics}

The quadratic regression (with $1 / x$ weighting) of the internally-standardized calibration curves had minimum $\mathrm{R}^{2}$ values of 0.9913 . The check calibration standards that were analyzed after every six samples were included in the standard curve preparation. The limits of detection (LODs) were determined by calculating the peak-to-peak signal to noise $(\mathrm{S} / \mathrm{N}=3)$ for the confirmation ion. The limits of quantitation (LOQs) were determined by calculating the $\mathrm{S} / \mathrm{N}$ (where $\mathrm{S} / \mathrm{N}=10$ ) for the quantitation ion (Table 3). 
To determine the intra-day variability for the standard and water sample, samples were repeatedly analyzed $(n=3)$ within one day. The variability as shown by the relative standard deviation (RSD, \%) was $19.4 \%$ or less for analytes in the standard, and $25.0 \%$ or less for those same analytes extracted from a spiked water sample by SPE. Inter-day variability for the standards was $15.6 \%$ or less (Table 3 ).

\section{Method Verification}

Composite samples of LWRP primary, secondary, and tertiary effluent were run with and without spiking (Table 4). Un-spiked control samples $(n=3)$ were prepared for analysis using the optimized SPE method. In these samples, all analytes were detected, though concentrations of OXC were below the LOQ $(4.2 \mathrm{ng} / \mathrm{mL})$. The concentrations of CBZ-epoxide were just at the LOQ and resulting precision was poor (RSD of 37.5\%). All other analytes (CBZ, CBZ-10-OH, and CBZ-DiOH) were found in appreciable quantities $(\geq 29.3 \mathrm{ng} / \mathrm{mL})$.

Spiked samples were prepared by adding $25 \mu \mathrm{L}$ of a Level 1 calibration standard that did not contain IS to aliquots of the composite samples. The spike concentrations per $125 \mathrm{~mL}$ composite sample ranged from $9 \mathrm{ng} / \mathrm{mL}$ (CBZ-DiOH) to $69.5 \mathrm{ng} / \mathrm{mL}$ (CBZ-10-OH). Spiked composite samples were also cleaned up prior to analysis using the SPE method. Resulting recoveries ranged from $44 \%(\mathrm{OXC})$ to $105 \%(\mathrm{CBZ})$ with reasonable precision $(<25 \%)$ with the exception of CBZ-DiOH (57\%).

\section{Optimization of Solid Phase Extraction Methodology}

Six different SPE columns were evaluated to optimize the efficient recovery of the analytes $\mathrm{CBZ}$ and CBZ-epoxide in a $500 \mathrm{ng} / \mathrm{mL}$ standard prepared in reagent water. The following 
columns were evaluated: Alltech C8 (200 mg/4 cc; Deerfield, IL), Supelco Discovery DSC-18 (500 mg/6 cc; Bellefonte, PA), Phenomenex strata-X (30 mg/1 cc; Torrance, CA), and Waters Oasis HLB (200 mg/5 cc glass cartridge; $150 \mathrm{mg} / 6 \mathrm{cc}$, and $60 \mathrm{mg} / 3 \mathrm{cc}$ ). All columns were conditioned, loaded, washed, and eluted using solvents and solvent volumes recommended per manufacturer's specifications. The resulting recoveries of CBZ and CBZ-epoxide were 93 $105 \%$ by external calibration and $104-110 \%$ by internal calibration when using the DSC-18, Alltech C8, and strata-X, and Oasis HLB $60 \mathrm{mg}$ columns. Use of the Oasis HLB $150 \mathrm{mg}$ columns resulted in recoveries of approximately $70 \%$ for $\mathrm{CBZ}$ and $75 \%$ for CBZ-E using either internal or external calibration methods. Recoveries by the glass Oasis HLB columns (200 mg/5 cc) resulted in approximately $30-37 \%$ for CBZ and CBZ-epoxide with RSD of $49-56 \%$.

The optimal peak shape was observed when the Oasis HLB $60 \mathrm{mg}$ columns or the Supelco DSC-18 columns were used for sample preparation and clean-up. To optimize the SPE method using one of these columns for large sample volumes, samples of reagent water $(400 \mathrm{~mL})$ were spiked with $50 \mu \mathrm{L}$ each with the reconstituted ClinCal standard containing all analytes of interest (including $\mathrm{CBZ}$, OXC, and metabolites). The samples were applied to the SPE columns at 0.6 $\mathrm{mL} / \mathrm{min}$ through either the conditioned Oasis HLB $60 \mathrm{mg}$ columns or Supelco DSC-18 columns by using a peristaltic pump as previously described. The columns were washed with 1 column volume of water and the analytes were eluted with $1 \mathrm{~mL}$ methanol into an amber glass autosampler vial. Ten $\mu \mathrm{L}$ of IS was added and mixed well. Two hundred $\mu \mathrm{L}$ aliquots were transferred to a clear autosampler vial and gently evaporated to dryness using ultra-high purity nitrogen. The samples were re-constituted in $100 \mu \mathrm{L}$ of water and placed into an autosampler vial insert prior to analysis by LC/MS/MS. Improved peak shape and optimized resolution between CBZ-epoxide and OXC were observed when samples were prepared in HPLC water as 
opposed to a solvent or solvent mix. Use of the Oasis HLB $60 \mathrm{mg}$ columns resulted in better recoveries for all analytes compared to the Supelco DSC-18 columns, with $73 \%$ recovery for CBZ, 70\% recovery for OXC, $67 \%$ recovery for CBZ-epoxide, $42 \%$ recovery for CBZ-10-OH, and $47 \%$ recovery of CBZ-DiOH from the larger volumes of reagent water $(400 \mathrm{~mL})$.

However, the recoveries of the more polar metabolites (CBZ-10-OH and CBZ-DiOH) were low when using the Oasis HLB $60 \mathrm{mg}$ columns. In a follow-up experiment, the Oasis HLB 150 mg columns were then re-evaluated as it was hypothesized that the increased sorbent mass would result in increased recoveries of the more polar metabolites when cleaning up large volumes of water. In this experiment, $10 \mu \mathrm{L}$ of the ClinCal standard mix was spiked into $1 \mathrm{~L}$ HPLC grade water. The spiked water samples were loaded onto conditioned Oasis HLB $60 \mathrm{mg}$ and $150 \mathrm{mg}$ columns ( $\mathrm{n}=3$ each) at $0.6 \mathrm{~mL} / \mathrm{min}$ by peristaltic pump as described. The columns were washed with reagent water and eluted with $0.5 \mathrm{~mL}$ methanol followed by $0.5 \mathrm{~mL}$ ethyl acetate. Again, 10 $\mu \mathrm{L}$ IS was added prior to mixing and evaporation of a $200 \mu \mathrm{L}$ aliquot. While the differences in recoveries for the different analytes between the two columns were not statistically significant $(P$ $\geq 0.1856$ by two-sided Student's $t$-test assuming equal variances), the recoveries of the analytes tended to be more precise (RSD of $11 \%$ or less) when using the Oasis $150 \mathrm{mg}$ columns. With these columns, the absolute recovery of CBZ from $1 \mathrm{~L}$ of water was $86 \%$, OXC at $97 \%$, CBZepoxide at $82 \%$, CBZ- $10-\mathrm{OH}$ at $51 \%$, and CBZ-DiOH at $59 \%$. The $10 \mu \mathrm{L}$ of IS was then added to the collected $1 \mathrm{~L}$ sample prior to SPE clean-up to correct for any losses of analytes.

\section{Quantification of CBZ, OXC, and Metabolites in Wastewater}

Samples of primary (before secondary treatment), secondary (after chlorination), and tertiary (after UV-treatment) wastewater were collected from the LWRP. The samples were analyzed in 
triplicate and results of analyses (mean concentrations with \% RSD) are shown in Table 5. The precision of the analyses, as indicated by \%RSD, were good for these collected environmental samples. At the primary stage of the LWRP, the maximum RSD was $15 \%$ for CBZ-epoxide, which had a mean concentration of $8.3 \mathrm{ng} / \mathrm{L}$. Concentrations of the compounds ranged from below the LOQ (for oxcarbazepine) to $392 \mathrm{ng} / \mathrm{L}$ for CBZ-DiOH. At the secondary treatment stage, the \%RSD was $26 \%$ (for CBZ) or lower for the five analytes. Concentrations were generally higher (with the exception of CBZ-DiOH) at the secondary stage, which has been previously observed (Leclercq et al., 2009). A lower concentration of CBZ-DiOH between the primary and secondary stages might indicate that this compound is somewhat susceptible to degradation by chlorination, though Benotti and colleagues have indicated that CBZ degradation by chlorinating processes is pH-dependent and is measureable when WWTPs use chlorination processes for disinfection over ozone treatment (Benotti et al., 2009). Recent work by Rosal et al. showed that carbamazepine required $\sim 130 \mu \mathrm{M}$ ozone for degradation (Rosal et al., 2010). In summary, there were no statistically significant differences in concentrations among the three sampling sites for any of the analytes, with the exception of OXC. OXC concentrations were below the LOQ at both the primary and secondary treatment sampling sites.

In general, the measured concentrations presented here compare well to data obtained by Leclercq et al. in their survey of $\mathrm{CBZ}$, OXC, and metabolite concentrations at three sewage treatment plants in France (Leclercq et al., 2009) and Miao and Metcalfe in their survey of a WWTP in Ontario, Canada (Miao et al., 2005). In the published papers by Leclercq and Miao, CBZ-DiOH concentrations ranged from 311 to $1415 \mathrm{ng} / \mathrm{L}$, compared to the $347-392 \mathrm{ng} / \mathrm{L}$ we present in Table 5. Because CBZ-DiOH is a metabolite of both $\mathrm{CBZ}$ and $\mathrm{OXC}$, it was anticipated that this major metabolite would be detected at higher concentrations than either of 
the parent drugs or primary metabolites (Miao and Metcalfe, 2003). Additionally, Leclercq et al. determined that CBZ-epoxide concentrations at influent and effluent sampling sites was less than $30 \mathrm{ng} / \mathrm{L}$ (Leclercq et al., 2009), which compared well to the concentrations of $10.3 \mathrm{ng} / \mathrm{L}$ or less as we determined. Miao determined the CBZ-epoxide had a mean concentration of $19.1 \mathrm{ng} / \mathrm{L}$ in treated wastewater at the Canadian WWTP (Miao et al., 2005). Concentrations of CBZ-10-OH ranged from below the LOQ to $1065 \mathrm{ng} / \mathrm{L}$ in the samples from France (Leclercq et al., 2009), and $32.5 \mathrm{ng} / \mathrm{L}$ in Canada (Miao et al., 2005) compared to the 354 to $429 \mathrm{ng} / \mathrm{L}$ levels determined here. The CBZ data compared favorably as well, with concentrations from 112 to $416 \mathrm{ng} / \mathrm{L}$ in the previously mentioned French and Canadian samples (Leclercq et al., 2009; Miao et al., 2005) and $117 \mathrm{ng} / \mathrm{L}$ in samples at a Spanish sewage treatment plant (Rosal et al., 2010) versus the 129 - $181 \mathrm{ng} / \mathrm{L}$ data presented here (Table 5). Trenholm and colleagues measured CBZ by on-line SPE with LC/MS/MS detection and found CBZ concentrations ranging from approximately 200 to $400 \mathrm{ng} / \mathrm{L}$ in wastewater effluent and water recharge basin samples from Nevada (Trenholm et al., 2009). The data was not consistent, however, with regards to OXC. We determined that concentrations of this parent drug ranged from $13.7 \mathrm{ng} / \mathrm{L}$ to below the LOQ at the three sampling sites. In the sampled French sewage treatment plants, the levels of OXC ranged from 51 to 476

ng/L. Furthermore, removal rates at the three sampled sewage treatment plants in the French study had widely varying removal rates of these drugs and their metabolites (Leclercq et al., 2009).

\section{Analyte Stability}

One hundred $\mu \mathrm{L}$ of Level 1 calibration standard (that did not contain the IS) were added to $125 \mathrm{~mL}$ effluent matrix samples. A set of three samples from each of the sampling areas was 
processed by clean-up, extraction, and analysis by LC/MS/MS immediately after adding and mixing the aliquot of Level 1 calibration standard. A second set of three samples from each study area was stored at $4{ }^{\circ} \mathrm{C}$ for one week prior being process as described above. The results of the holding time study are shown in Table 6.

Briefly, the concentrations of $\mathrm{CBZ}, \mathrm{OXC}$, and metabolites recovered were comparable to results from the method validation experiments previously described. Generally, all the matrix spiked samples from each study area showed no significant change in measured analyte concentrations when comparing samples processed at day zero of experiment to samples stored at $4{ }^{\circ} \mathrm{C}$ and processed after seven days. Concentration measurements of CBZ-10-OH for the effluent matrix spikes of the primary treatment station were lower than the other two effluent sampling locations for both the day 0 and 7 processed samples. The mean of the day 7 samples from the primary effluents were the lowest CBZ-10-OH concentrations measured and notably less than day $0(P=0.0330$; Table 6).

In summary, a method for the quantitation of $\mathrm{CBZ}, \mathrm{OXC}$, and metabolites using an isotopically-labeled internal standard was validated and used to assess concentrations of this class of compounds at a U.S.-based wastewater treatment plant. Future work will focus on using this quantitative method to characterize $\mathrm{CBZ}, \mathrm{OXC}$, and metabolite concentrations in sampled groundwater to determine the extent of contamination by WWTP effluent. Additionally, future plans include the sampling of surface waters and San Francisco Bay water to determine the extent of further contamination and mixing downstream of our sampled WWTP.

\section{ACKNOWLEDGMENTS}


The authors thank Roald Leif (LLNL) for his assistance in setting up the SPE extraction apparatus for large volume samples, Kevin Kepler and David Stoops of Livermore Water Reclamation Plant, and Allen Grayson (LLNL) for sampling assistance. Funding from the California State Water Resources Control Board GAMA program (No. 08-075-250-0) is gratefully acknowledged. This work was performed under the auspices of the U.S. Department of Energy by Lawrence Livermore National Laboratory under Contract DE-AC52-07NA27344.

\section{LITERATURE CITED}

1. Leclercq M, Mathieu O, Gomez E, Casellas C, Fenet H, Hillaire-Buys D. Presence and fate of carbamazepine, oxcarbazepine, and seven of their metabolites at wastewater treatment plants. Arch Environ Contam Toxicol. 2009;56:408-15.

2. Vieno N, Tuhkanen T, Kronberg L. Elimination of pharmaceuticals in sewage treatment plants in Finland. Water Res. 2007;41:1001-12.

3. Miao X-S, Yang J-J, Metcalfe CD. Carbamazepine and its metabolites in wastewater and biosolids in a municipal wastewater treatment plant. Environ Sci Technol. 2005;39:7469-75.

4. Miao X-S, Metcalfe CD. Determination of carbamazepine and its metabolites in aqueous samples using liquid chromatography-electrospray tandem mass spectrometry. Anal Chem. 2003;75:3731-8.

5. Gagne F, Blaise C, Andre C. Occurrence of the pharmaceutical products in a municipal effluent and toxicity to rainbow trout (Oncorhynchus mykiss) hepatocytes. Ecotoxicol Environ Safety. 2006;64:329-36.

6. Martin-Diaz ML, Gagne F, Blaise C. The use of biochemical responses to assess ecotoxicological effects of Pharmaceutical and Personal Care Products (PPCPs) after injection in the mussel Elliptio complanata. Environ Toxicol Pharmacol. 2009;28:237-42.

7. Benotti MJ, Trenholm RA, Vanderford BJ, Holady JC, Stanford BD, Snyder SA. Pharmaceuticals and endocrine disrupting compounds in U.S. drinking water. Environ Sci Technol. 2009;43:597-603.

8. Kupferberg HJ. GLC determination of carbamazepine in plasma. J Pharm Sci. 1982;61:2846.

9. Baker KM, Csetenyi J, Frigergio A, Morselli PL. 10,11-Dihydro-10,11-dihydroxy-5Hdibenz[b,f]azepine-5-carboxamide, a metabolite of carbamazepine isolated from human and rat urine. J Med Chem. 1973;16:703-5.

10. von Unruh GE, Paar WD. Gas chromatographic/mass spectrometric assays for oxcarbazepine and its main metabolites, 10-hydroxy-carbazepine and carbazepine-10,11-trans-diol. Biomed Environ Mass Spectrom. 1986;13:651-6.

11. Maggs JL, Pirmohamed M, Kitteringham NR, Park BK. Characterization of the metabolites of carbamazepine in patient urine by liquid chromatography/mass spectrometry. Drug Metab Dispos. 1997;25:275-80. 
12. Breton H, Cociglio M, Bressolle F, Peyriere H, Blayac JP, Hillaire-Buys D. Liquid chromatography-electrospray mass spectrometry determination of carbamazepine, oxcarbazepine and eith of their metabolites in human plasma. J Chromatogr B. 2005;828:8090.

13. de Sousa Maia MB, do Nascimento DF, Martins IL, Cunha AN, de Lima FEG, Bezerra FAF, et al. Simultaneous quantitative analysis of oxcarbazepine and 10,11-dihydro-10hydroxycarbamazepine in human plasma by liquid chromatography-electrospray tandem mass spectrometry. J Pharm Biomed Anal. 2007;45:304-11.

14. Corso G, D'Apolito O, Paglia G. The accuracy of oxcarbazepine (OXC) quantification by a liquid chromatography/tandem mass spectrometry method is influenced by the ion source fragmentation of its metabolite trans-diol-carbazepine (DHD). [Letter]. Rapid Commun Mass Spectrom. 2007;21:269-72.

15. Trenholm RA, Vanderford BJ, Snyder SA. On-line solid phase extraction LC-MS/MS analysis of pharmaceutical indicators in water: A green alternative to conventional methods. Talanta. 2009;79:1425-32.

16. Vanderford BJ, Pearson RA, Rexing DJ, Snyder SA. Analysis of endocrine disruptors, pharmaceuticals, and personal care products in water using liquid chromatography/tandem mass spectrometry. Anal Chem. 2003;75:6265-74.

17. Kinney CA, Furlong ET, Werner SL, Cahill JD. Presence and distribution of wastewaterderived pharmaceuticals in soil irrigated with reclaimed water. Environ Toxicol Chem. 2006;25:317-26.

18. Rosal R, Rodriguez A, Perdigon-Melon JA, Petre A, Garcia-Calvo E, Jose Gomez M, et al. Occurrence of emerging pollutants in urban wastewater and their removal through biological treatment followed by ozonation. Water Res. 2010;44:578-88. 


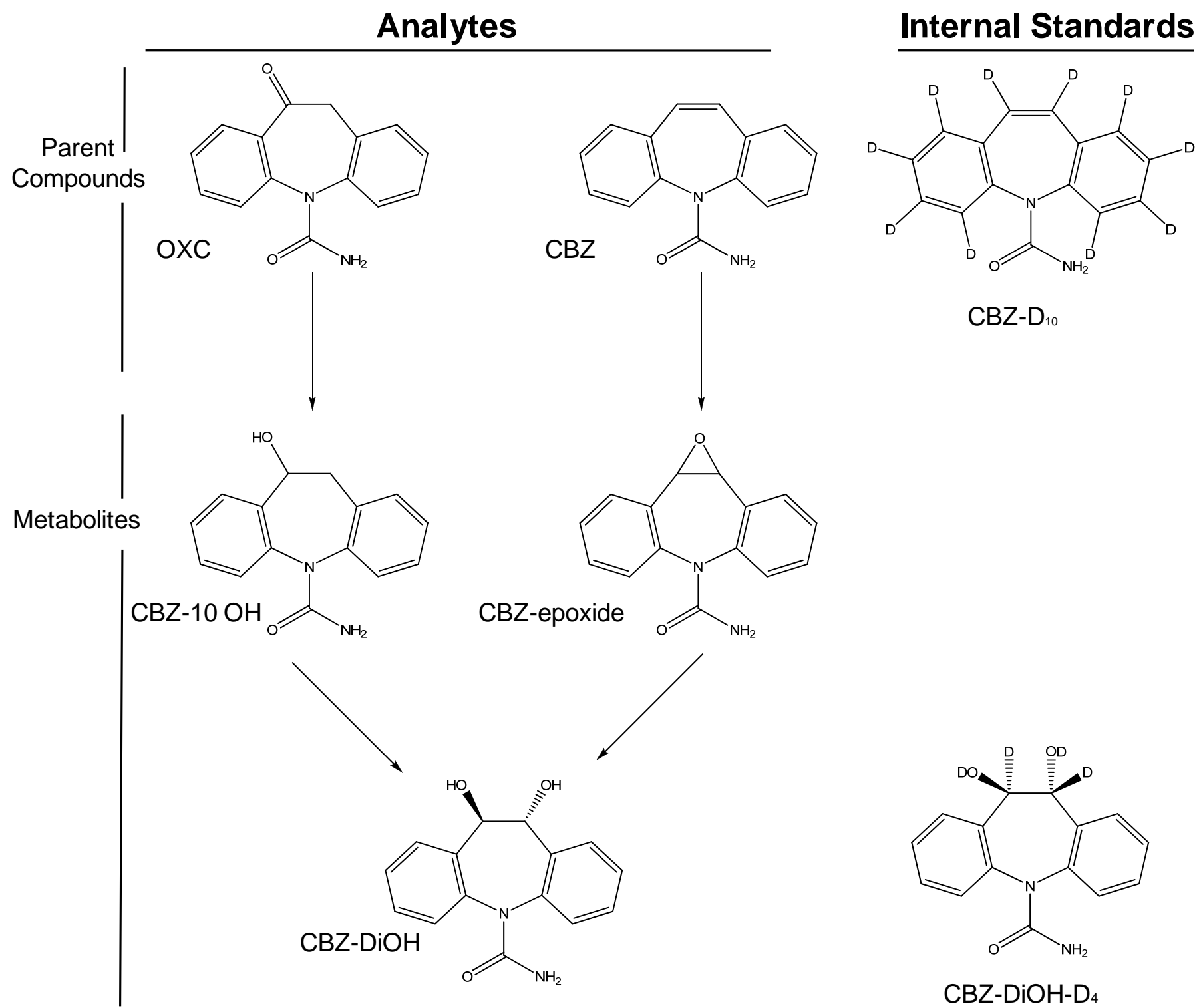

Figure 1: Analytes. Structures of analytes carbamazepine (CBZ) and oxcarbazepine (OXC) and their metabolites, including carbamazepine-epoxide (CBZ-epoxide), 10, 11-dihydro-10hydroxycarbamazepine (CBZ-10OH), 10,11-dihydro-10,11-dihydroxycarbamazepine (CBZ$\mathrm{DiOH}$ ), and internal standards CBZ- $\mathrm{D}_{10}$ and CBZ-DiOH-D 4 . 


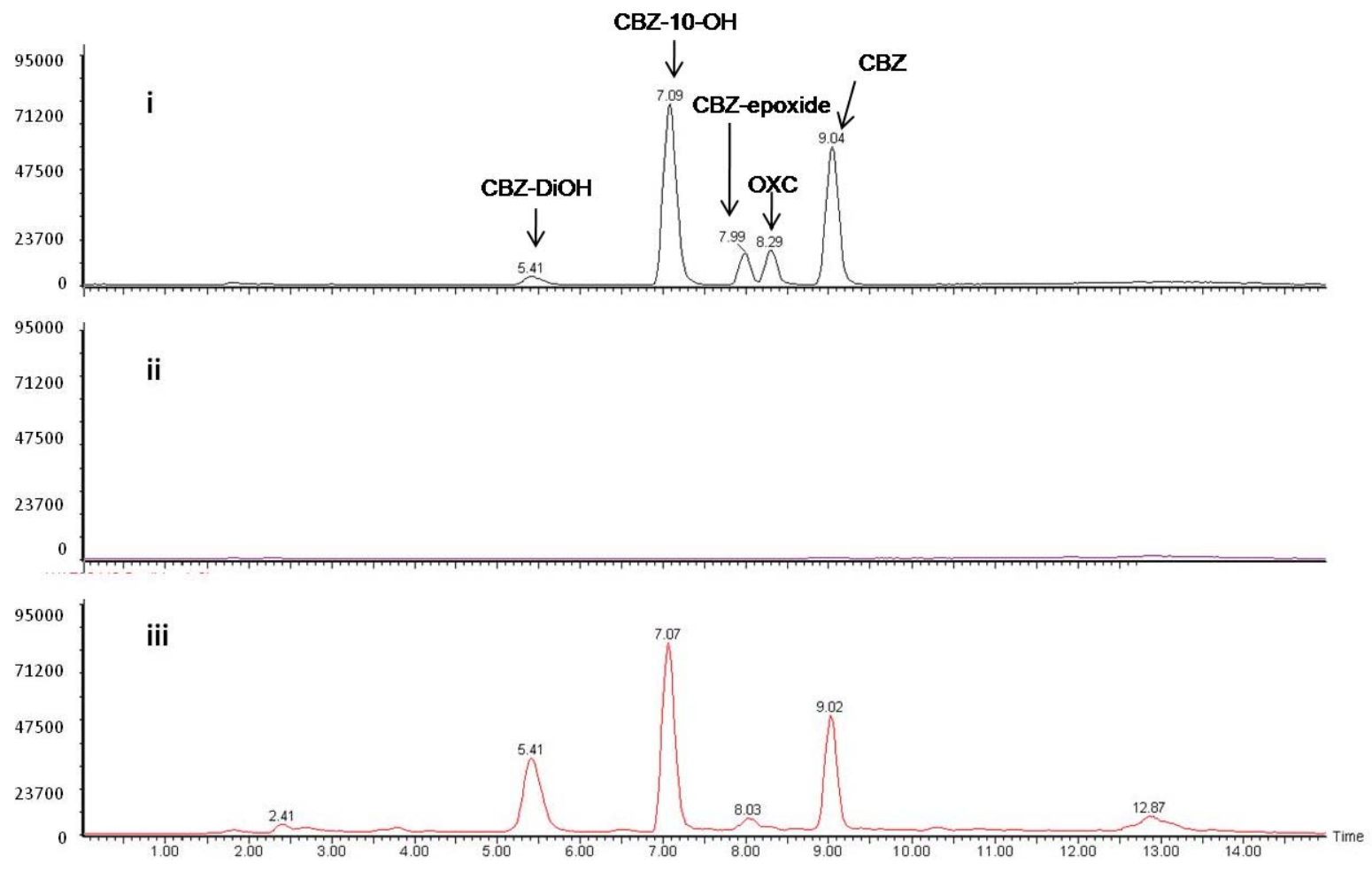

Figure 2: Chromatograms. Example chromatograms of count rate versus elution time of a standard at Level 6 (i), reagent water blank prepared by solid phase extraction (SPE) (ii), and composite water sample prepared by SPE as described (iii). 


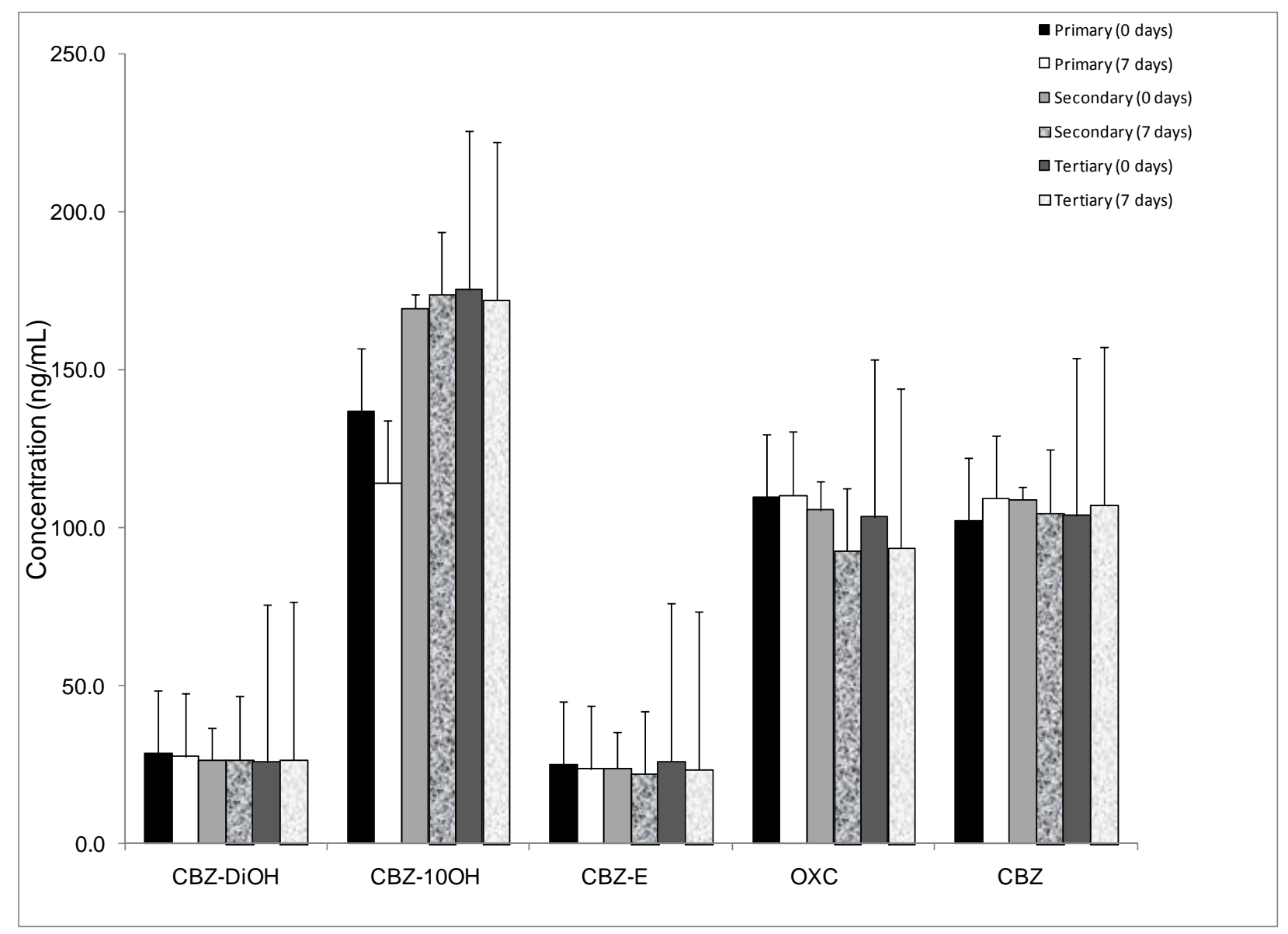

Figure 3: Analyte Stability. Holding time study of primary, secondary, and tertiary effluents with mean concentrations of $\mathrm{CBZ}, \mathrm{OXC}$, and metabolites. Mean concentration $(\mathrm{ng} / \mathrm{mL})$ is represented by solid bar; uncertainty (1 SD) is represented by error bar. 
Table 1: Calibration Standards.

Concentrations (ng/mL) of Analytes and IS in Calibration Standards Prepared in HPLC-Grade Water

\begin{tabular}{|c|c|c|c|c|c|c|}
\hline \multirow[b]{2}{*}{$\begin{array}{c}\text { standard } \\
\text { level }\end{array}$} & \multicolumn{5}{|c|}{ analyte } & \multirow{2}{*}{$\frac{\mathrm{IS}}{\mathrm{CBZ}-\mathrm{D}_{10}}$} \\
\hline & CBZ & $\mathrm{OXC}$ & $\begin{array}{c}\text { CBZ- } \\
\text { epoxide }\end{array}$ & $\begin{array}{c}\text { CBZ-10- } \\
\text { OH }\end{array}$ & $\begin{array}{l}\text { CBZ- } \\
\text { DiOH }\end{array}$ & \\
\hline 1 & 1100 & 2080 & 560 & 2780 & 360 & 10 \\
\hline 2 & 550 & 1040 & 280 & 1390 & 180 & 10 \\
\hline 3 & 225 & 520 & 140 & 695 & 90 & 10 \\
\hline 4 & 112.5 & 260 & 70 & 347.5 & 45 & 10 \\
\hline 5 & 55 & 104 & 28 & 139 & 18 & 10 \\
\hline 6 & 27.5 & 52 & 14 & 69.5 & 9 & 10 \\
\hline 7 & 11 & 20.8 & 5.6 & 27.8 & 3.6 & 10 \\
\hline 8 & 5.5 & 10.4 & 2.8 & 13.9 & 1.8 & 10 \\
\hline 9 & 2.2 & 4.2 & 1.1 & 5.6 & 0.72 & 10 \\
\hline 10 & 1.1 & 2.1 & 0.56 & 2.8 & 0.36 & 10 \\
\hline
\end{tabular}


Table 2: Instrument Settings.

Mass Spectrometer Settings for Analysis of CBZ, OXC, their Metabolites and an IsotopicallyLabeled Internal Standard (indicated by *) with Positive Electrospray Ionization

\begin{tabular}{|c|c|c|c|c|c|c|}
\hline \multirow[b]{2}{*}{$\begin{array}{c}\text { Analyte } \\
\text { or IS* }\end{array}$} & \multicolumn{3}{|c|}{ quantitation ion } & \multicolumn{3}{|c|}{ confirmation ion } \\
\hline & transition & $\begin{array}{l}\text { cone } \\
(\mathrm{V})\end{array}$ & $\begin{array}{l}\text { collisio } \\
\mathrm{n}(\mathrm{eV})\end{array}$ & transition & $\begin{array}{c}\text { cone } \\
(\mathrm{V})\end{array}$ & $\begin{array}{l}\text { collisio } \\
\mathrm{n}(\mathrm{eV})\end{array}$ \\
\hline & $\mathrm{m} / \mathrm{z} 237.1 \rightarrow$ & & & $\mathrm{m} / \mathrm{z} 237.1 \rightarrow$ & & \\
\hline $\mathrm{CBZ}$ & $\begin{array}{c}m / z \quad 194.2 \\
m / z ~ 253.1 \rightarrow\end{array}$ & 25 & 20 & $\begin{array}{c}m / z 192.2 \\
m / z 253.1 \rightarrow\end{array}$ & 25 & 20 \\
\hline $\mathrm{OXC}$ & m/z 236.3 & 15 & 10 & m/z 210.5 & 15 & 15 \\
\hline CBZ- & $\mathrm{m} / \mathrm{z} 253.1 \rightarrow$ & & & $\mathrm{m} / \mathrm{z} 253.1 \rightarrow$ & & \\
\hline epoxide & m/z 180.2 & 15 & 15 & m/z 236.3 & 15 & 12 \\
\hline CBZ- & $\mathrm{m} / \mathrm{z} 255.1 \rightarrow$ & & & $\mathrm{m} / \mathrm{z} 255.1 \rightarrow$ & & \\
\hline $10-\mathrm{OH}$ & m/z 236.1 & 15 & 10 & m/z 194.1 & 15 & 15 \\
\hline CBZ- & $\mathrm{m} / \mathrm{z} 271.1 \rightarrow$ & & & $\mathrm{m} / \mathrm{z} 271.1 \rightarrow$ & & \\
\hline $\mathrm{DiOH}$ & m/z 253.4 & 15 & 15 & m/z 236.1 & 15 & 15 \\
\hline CBZ- & $\mathrm{m} / \mathrm{z} 247.2 \rightarrow$ & & & & & \\
\hline $\mathrm{D}_{10} *$ & m/z 204.3 & 25 & 18 & - & - & - \\
\hline
\end{tabular}


Table 3: Method Figures of Merit.

Method Characteristics of CBZ, OXC, and Metabolites as Determined by LC/MS/MS

\begin{tabular}{|c|c|c|c|c|c|c|}
\hline \multirow[b]{2}{*}{ analyte } & \multirow[b]{2}{*}{$\mathrm{R}^{2}$} & \multirow[b]{2}{*}{$\begin{array}{c}\text { LOD } \\
(\mathrm{ng} / \mathrm{mL})\end{array}$} & \multirow[b]{2}{*}{$\begin{array}{c}\mathrm{LOQ} \\
(\mathrm{ng} / \mathrm{mL})\end{array}$} & \multicolumn{2}{|c|}{$\begin{array}{c}\text { Intra-day variability } \\
(\%)\end{array}$} & \multirow{2}{*}{$\begin{array}{c}\begin{array}{c}\text { Inter-day } \\
\text { variability } \\
(\%)\end{array} \\
\begin{array}{c}\text { Standard } \\
(\mathrm{n}=6)\end{array}\end{array}$} \\
\hline & & & & $\begin{array}{l}\text { Standard } \\
(\mathrm{n} \geq 3)\end{array}$ & $\begin{array}{c}\text { Water } \\
\text { Sample } \\
(\mathrm{n}=3)\end{array}$ & \\
\hline CBZ & 0.9918 & $<1.1$ & 1.1 & 6.9 & 25.0 & 15.6 \\
\hline OXC & 0.9952 & $<2.1$ & 2.1 & 3.1 & 3.3 & 9.7 \\
\hline $\begin{array}{l}\text { CBZ- } \\
\text { epoxide }\end{array}$ & 0.9917 & $<0.56$ & 0.56 & 11.4 & 19.9 & 13.0 \\
\hline $\begin{array}{l}\text { CBZ- } \\
10-\mathrm{OH}\end{array}$ & 0.9959 & $<2.8$ & 5.56 & 19.4 & 11.8 & 15.4 \\
\hline $\begin{array}{l}\text { CBZ- } \\
\mathrm{DiOH}\end{array}$ & 0.9982 & 1.8 & 3.6 & 11.3 & 10.3 & 12.3 \\
\hline
\end{tabular}


Table 4: Method Verification

Measured background ("Control"), Added Spike, and Control + Added Spike concentrations $(\mathrm{ng} / \mathrm{mL})$ in composite effluent samples. Uncertainties $(\% \mathrm{RSD})$ are based on replicate experiments $(n=3)$.

\begin{tabular}{ccccc}
\hline Analyte & $\begin{array}{c}\text { Control } \\
(\mathrm{RSD}) \\
(\mathrm{ng} / \mathrm{mL})\end{array}$ & $\begin{array}{c}\text { Added } \\
\text { Spike } \\
(\mathrm{ng} / \mathrm{mL})\end{array}$ & $\begin{array}{c}\text { Measured } \\
\text { Control }+ \text { Spike } \\
(\mathrm{ng} / \mathrm{mL})\end{array}$ & $\begin{array}{c}\text { Recovery }(\mathrm{RSD}) \\
(\%)\end{array}$ \\
\hline $\mathrm{CBZ}$ & $29.3(13 \%)$ & 27.5 & 59.6 & $105 \%(25 \%)$ \\
OXC & $<\mathrm{LOQ}$ & 52.0 & 22.9 & $44 \%(3 \%)$ \\
CBZ-epoxide & $1.6(8 \%)$ & 14.0 & 10.5 & $67 \%(7 \%)$ \\
CBZ-10-OH & $85.3(3 \%)$ & 69.5 & 140.6 & $91 \%(20 \%)$ \\
CBZ-DiOH & $75.7(7 \%)$ & 9.0 & 83.7 & $99 \%(57 \%)$
\end{tabular}


Table 5: Quantification of CBZ, OXC, and Metabolites in Wastewater Mean Concentrations (RSD, \%) of CBZ, OXC, and Metabolites in Sampled Waters $(n=3), n g / L$

\begin{tabular}{ccccc}
\hline & $\begin{array}{c}\text { Primary } \\
\text { After primary, } \\
\text { before } \\
\text { secondary } \\
\text { treatment }\end{array}$ & $\begin{array}{c}\text { Secondary } \\
\text { Chlorinated } \\
\text { secondary } \\
\text { effluent }\end{array}$ & $\begin{array}{c}\text { Tertiary } \\
\text { Tertiary (post- } \\
\text { UV) effluent }\end{array}$ & $\begin{array}{c}\text { P values by } \\
\text { ANOVA }\end{array}$ \\
\hline CBZ-DiOH & $392(4.5 \%)$ & $354(10 \%)$ & $347(10 \%)$ & 0.2268 \\
CBZ-10-OH & $354(1.0 \%)$ & $429(12 \%)$ & $399(8.5 \%)$ & 0.2331 \\
CBZ-epoxide & $8.3(15 \%)$ & $10.3(20 \%)$ & $7.1(12 \%)$ & 0.0867 \\
OXC & Below LOQ & Below LOQ & $13.7(26 \%)$ & 0.0118 \\
CBZ & $153(11 \%)$ & $181(26 \%)$ & $129(21 \%)$ & 0.2350
\end{tabular}


Table 6: Analyte Stability

Matrix Spiking Level (ng/mL) and Mean Concentrations $(\mathrm{ng} / \mathrm{mL})$ of Primary, Secondary, and Tertiary Effluents (with Relative Standard Deviation, \%) of CBZ, OXC, and Metabolite Analytes Extractions Processed at Day $0(n=3)$ and Day $7(n=3)$. Values indicated in bold font and boxed are significantly different at $P<0.05$ (by Student's $t$-test) for Day 0 versus Day 7 analyses.

\begin{tabular}{|c|c|c|c|c|c|c|c|}
\hline \multirow{3}{*}{ Analyte } & \multirow{3}{*}{ Spike } & \multicolumn{6}{|c|}{ Mean Concentration (\%RSD) } \\
\hline & & \multicolumn{2}{|c|}{ Primary } & \multicolumn{2}{|c|}{ Secondary } & \multicolumn{2}{|c|}{ Tertiary } \\
\hline & & Day 0 & Day 7 & Day 7 & Day 0 & Day 0 & Day 7 \\
\hline $\mathrm{CBZ}$ & 110 & $\begin{array}{l}102.2 \\
(14.5)\end{array}$ & $\begin{array}{l}109.2 \\
(3.2)\end{array}$ & $\begin{array}{c}108.8 \\
(4.1)\end{array}$ & $\begin{array}{c}104.8 \\
(6.2)\end{array}$ & $\begin{array}{c}103.8 \\
(1.1)\end{array}$ & $107(7.0)$ \\
\hline $\mathrm{OXC}$ & 208 & $\begin{array}{l}109.5 \\
(16.0)\end{array}$ & $\begin{array}{l}110.3 \\
(4.6)\end{array}$ & $\begin{array}{l}105.7 \\
(9.1)\end{array}$ & $\begin{array}{l}92.6 \\
(4.1)\end{array}$ & $\begin{array}{l}103.3 \\
(14.7)\end{array}$ & $\begin{array}{c}93.9 \\
(13.0)\end{array}$ \\
\hline CBZ-epoxide & 56 & $\begin{array}{l}25.2 \\
(2.5)\end{array}$ & $\begin{array}{l}23.7 \\
(7.7)\end{array}$ & $\begin{array}{c}23.9 \\
(11.6)\end{array}$ & $\begin{array}{l}22.1 \\
(6.4)\end{array}$ & $\begin{array}{l}26.0 \\
(8.1)\end{array}$ & $\begin{array}{c}23.5 \\
(16.7)\end{array}$ \\
\hline CBZ-10-OH & 278 & $\begin{array}{c}136.8 \\
(7.2)\end{array}$ & $\begin{array}{c}114.0 \\
(3.6)\end{array}$ & $\begin{array}{l}169.4 \\
(4.5)\end{array}$ & $\begin{array}{l}173.6 \\
(2.9)\end{array}$ & $\begin{array}{c}175.4 \\
(6.3)\end{array}$ & $\begin{array}{l}171.9 \\
(9.3)\end{array}$ \\
\hline CBZ-DiOH & 36 & $\begin{array}{c}28.7 \\
(20.7)\end{array}$ & $\begin{array}{c}27.5 \\
(10.3)\end{array}$ & $\begin{array}{c}26.5 \\
(10.3)\end{array}$ & $\begin{array}{c}26.7 \\
(11.4)\end{array}$ & $\begin{array}{c}25.8 \\
(21.9)\end{array}$ & $\begin{array}{c}26.7 \\
(13.1)\end{array}$ \\
\hline
\end{tabular}




\section{Literature Cited}

Baker, K. M., Csetenyi, J., Frigergio, A., and Morselli, P. L., 1973. 10,11-Dihydro-10,11dihydroxy-5H-dibenz [b,f]azepine-5-carboxamide, a metabolite of carbamazepine isolated from human and rat urine. J. Med. Chem. 16, 703-705.

Benotti, M. J., Trenholm, R. A., Vanderford, B. J., Holady, J. C., Stanford, B. D., and Snyder, S. A., 2009. Pharmaceuticals and endocrine disrupting compounds in U.S. drinking water. Environ. Sci. Technol. 43, 597-603.

Breton, H., Cociglio, M., Bressolle, F., Peyriere, H., Blayac, J. P., and Hillaire-Buys, D., 2005. Liquid chromatography-electrospray mass spectrometry determination of carbamazepine, oxcarbazepine and eith of their metabolites in human plasma. $J$. Chromatogr. B 828, 80-90.

Corso, G., D'Apolito, O., and Paglia, G., 2007. The accuracy of oxcarbazepine (OXC) quantification by a liquid chromatography/tandem mass spectrometry method is influenced by the ion source fragmentation of its metabolite trans-diol-carbazepine (DHD). [Letter]. Rapid Commun. Mass Spectrom. 21, 269-272.

Gagne, F., Blaise, C., and Andre, C., 2006. Occurrence of the pharmaceutical products in a municipal effluent and toxicity to rainbow trout (Oncorhynchus mykiss) hepatocytes. Ecotoxicol. Environ. Safety 64, 329-336.

Kinney, C. A., Furlong, E. T., Werner, S. L., and Cahill, J. D., 2006. Presence and distribution of wastewater-derived pharmaceuticals in soil irrigated with reclaimed water. Environ. Toxicol. Chem. 25, 317-326.

Kupferberg, H. J., 1982. GLC determination of carbamazepine in plasma. J. Pharm. Sci. 61, 284-286.

Leclercq, M., Mathieu, O., Gomez, E., Casellas, C., Fenet, H., and Hillaire-Buys, D., 2009. Presence and fate of carbamazepine, oxcarbazepine, and seven of their metabolites at wastewater treatment plants. Arch. Environ. Contam. Toxicol. 56, 408-415.

Maggs, J. L., Pirmohamed, M., Kitteringham, N. R., and Park, B. K., 1997. Characterization of the metabolites of carbamazepine in patient urine by liquid chromatography/mass spectrometry. Drug Metab Dispos 25, 275-280.

Maia, M. B. D. S., do Nascimento, D. F., Martins, I. L., Cunha, A. N., de Lima, F. E. G., Bezerra, F. A. F., de Moraes, M. D., and de Moraes, M. E. A., 2007. Simultaneous quantitative analysis of oxcarbazepine and 10,11-dihydro-10-hydroxycarbamazepine in human plasma by liquid chromatography-electro spray tandem mass spectrometry. Journal of Pharmaceutical and Biomedical Analysis 45, 304-311.

Martin-Diaz, M. L., Gagne, F., and Blaise, C., 2009. The use of biochemical responses to assess ecotoxicological effects of Pharmaceutical and Personal Care Products (PPCPs) after injection in the mussel Elliptio complanata. Environ. Toxicol. Pharmacol. 28, 237242.

Miao, X.-S. and Metcalfe, C. D., 2003. Determination of carbamazepine and its metabolites in aqueous samples using liquid chromatography-electrospray tandem mass spectrometry. Anal. Chem. 75, 3731-3738.

Miao, X.-S., Yang, J.-J., and Metcalfe, C. D., 2005. Carbamazepine and its metabolites in wastewater and biosolids in a municipal wastewater treatment plant. Environ. Sci. Technol. 39, 7469-7475. 
Rosal, R., Rodriguez, A., Perdigon-Melon, J. A., Petre, A., Garcia-Calvo, E., Jose Gomez, M., Aguera, A., and Fernandez-Alba, A. R., 2010. Occurrence of emerging pollutants in urban wastewater and their removal through biological treatment followed by ozonation. Water Res. 44, 578-588.

Trenholm, R. A., Vanderford, B. J., and Snyder, S. A., 2009. On-line solid phase extraction LC-MS/MS analysis of pharmaceutical indicators in water: A green alternative to conventional methods. Talanta 79, 1425-1432.

von Unruh, G. E. and Paar, W. D., 1986. Gas chromatographic/mass spectrometric assays for oxcarbazepine and its main metabolites, 10-hydroxy-carbazepine and carbazepine10,11-trans-diol. Biomed. Environ. Mass Spectrom. 13, 651-656.

Vanderford, B. J., Pearson, R. A., Rexing, D. J., and Snyder, S. A., 2003. Analysis of endocrine disruptors, pharmaceuticals, and personal care products in water using liquid chromatography/tandem mass spectrometry. Anal. Chem. 75, 6265-6274.

Vieno, N., Tuhkanen, T., and Kronberg, L., 2007. Elimination of pharmaceuticals in sewage treatment plants in Finland. Water Res. 41, 1001-1012. 


\section{Appendix A: \\ Protocol for the Extraction, Clean-Up, and Analysis of Carbamazepine and Related Metabolites from Collected Water Samples by Solid Phase Extraction with Analysis by LC/MS/MS}

Objective: This method describes the extraction of carbamazepine and related metabolites from water samples prior to analysis by liquid chromatography tandem mass spectrometry (LC/MS/MS).

\section{Chemicals and Materials:}

1. HPLC-grade solvents: methanol, reagent water, acetonitrile, and ethyl acetate

2. MS-grade mobile phase modifiers: formic acid

3. Standards: $100 \mu \mathrm{g} / \mathrm{mL}$ carbamazepine- $D_{10}$ (used as internal standard) prepared in methanol from Cambridge Isotope Laboratories; ClinCal calibrant mix of carbamazepine (CBZ), oxcarbazepine (OXC), and metabolites (CBZ-DiOH, CBZ-10OH, and CBZ-epoxide)

4. Materials: Oasis HLB $150 \mathrm{mg} / 6$ cc solid phase extraction (SPE) cartridges (Waters Corp, part no. 186003365, lot no. 088A39040B), XBridge C18 analytical HPLC column (Waters Corp., $15 \mathrm{~mm} \times 2.1 \mathrm{~mm}$ i.d., $3.5 \mu \mathrm{m}$ particle size), Teflon tubing with weights, SPE column fittings, peristaltic pump, autosampler vials and lids, autosampler inserts

\section{Protocol:}

1. Pre-clean all Teflon tubing with methanol by pumping methanol through tubing using peristaltic pump. Rinse Teflon tubing with reagent grade water after methanol wash before using for the clean-up of collected water samples.

2. Attach Oasis HLB SPE cartridges to yellow peristaltic pump tubing using the clear connectors. Turn the pump on and operate at speed 600.

3. Condition Oasis HLB SPE cartridges with 2 column volumes (about $12 \mathrm{~mL}$ ) methanol followed by 1 column volume of reagent water. Once the reagent water has almost completely passed through the SPE cartridges, turn the peristaltic pump off. Refill the cartridges with one more column volume of distilled water.

4. Prepare water samples by adding $10 \mu \mathrm{L}$ of internal standard (IS) CBZ- $\mathrm{D}_{10}$ (prepared at 1

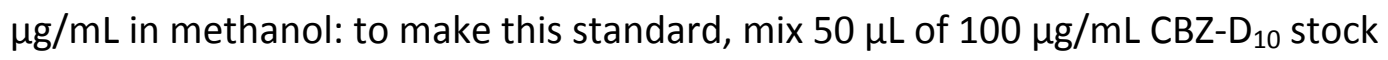
solution with $4.950 \mathrm{~mL}$ of methanol. Mix well). Mix the water samples well. Water sample volumes range from $125 \mathrm{~mL}$ to $500 \mathrm{~mL}$, depending on what the sample is and the expected concentration of CBZ.

5. Drop the weighted end of the Teflon tubing into the water sample that now contains the IS. The Teflon tubing has been fitted with a white SPE connector. Fit this connector piece into the top of the Oasis HLB SPE cartridge that contains 1 column volume of reagent water.

6. Make sure that the various fittings and joints of tubing connections in the system are air-tight. Turn on the peristaltic pump and make sure than the water sample 
containing IS starts to get pumped through the Teflon tubing into the SPE cartridge. This may take several minutes.

7. Once the samples are reliably being pumped into the SPE cartridge, you can check occasionally throughout the day. A $125-\mathrm{mL}$ sample will take about 4 hours to filter, whereas a $1 \mathrm{~L}$ sample might take close to 36 hours. Just make sure that the system's fittings are tight and that everything is well connected.

8. Once the entire water sample has been filtered through the SPE cartridge, you can remove the white SPE connector that holds the Teflon tubing. Leave the SPE cartridge connected to the yellow peristaltic pump tubing. Add $\sim 2 \mathrm{~mL}$ reagent water to wash the column. Once the water and moved through the SPE sorbent bed, you can remove the SPE column from the peristaltic pump.

9. Put the SPE column onto a SPE vacuum manifold. Apply light vacuum to dry the column out of any excess water. Place an autosampler vial under the column to collect the following methanol and ethyl acetate fractions: first, add $0.5 \mathrm{~mL}$ methanol and apply the vacuum (be sure to collect this fraction!!!) and then add $0.5 \mathrm{~mL}$ ethyl acetate (collect this fraction into the same autosampler vial that contains the methanol fraction!!!). Cap the autosampler vial and mix well.

10. When you're ready for LC/MS/MS analysis, take a $200 \mu \mathrm{L}$ aliquot of the methanol/ethyl acetate fraction and place into a clean autosampler vial. Using high-purity nitrogen, slowly and carefully evaporate the sample (this can be just to dryness). Add $75 \mu \mathrm{L}$ reagent water and mix well. Place this new aqueous mix into an autosampler insert and cap the vial. Store at $4{ }^{\circ} \mathrm{C}$ until analysis.

\section{LC/MS/MS Analysis:}

1. A Waters 2795 Alliance high performance liquid chromatograph with a Waters Micromass Quattro Micro api triple quadrupole mass spectrometer (LC/MS/MS) is used for the analyses of CBZ and metabolites.

2. Calibrate the instrument monthly using a sodium iodide/cesium iodide calibrant. This solution can be found in the refrigerator in the lab.

3. The instrument was previously tuned for carbamazepine analyses. Use the following methods to run the instrument (note: all are found at C: \MassLynx\Janel\CBZ.pro)

a. Tune file: CBZ.ipr

b. Inlet file: CBZ.wat

c. MS method: CBZ.exp

d. Processing method: CBZ.mdb

4. The tune parameters are as follows:

a. Capillary voltage: $3.0 \mathrm{kV}$ (positive ESI)

b. Cone voltage: depends on analyte (ranges from 15 to $25 \mathrm{~V}$ )

c. RF lens: $0.2 \mathrm{~V}$

d. Extractor: $2 \mathrm{~V}$

e. Source temp: $120^{\circ} \mathrm{C}$

f. Desolvation temp: $300{ }^{\circ} \mathrm{C}$

g. Desolvation gas: $500 \mathrm{~L} / \mathrm{h}$ 
h. Cone gas: $45 \mathrm{~L} / \mathrm{h}$

i. Low and high mass, resolution 1: 14.5

j. Ion energy 1: 0.5

k. Entrance: $-1 \mathrm{eV}$

I. Collision energy, eV: depends on analyte and product ion (ranges from $10-20$ eV)

m. Exit energy: $2 \mathrm{eV}$

n. Low and high mass, resolution 2: 15.0

o. Ion energy 2: 1.5

p. Multiplier: 650

q. Inter-scan delay: 0.1

r. Span: 0

s. Dwell time: $0.1 \mathrm{~ms}$

t. Inter-channel delay: 0.2

u. Repeats: 1

5. HPLC parameters:

a. Column: Waters XBridge C18 $(150 \times 2.1 \mathrm{~mm}$ i.d., $3.5 \mu \mathrm{m})$

b. Mobile phase A: Water $+0.1 \%$ formic acid

c. Mobile phase B: Acetonitrile $+0.1 \%$ formic acid

d. Strong needle wash: 40/40/20 acetonitrile/methanol/water

e. Weak needle wash: 90/10 water/acetonitrile

f. Injection volume: $20 \mu \mathrm{L}$

g. Flow rate: $200 \mu \mathrm{L} / \mathrm{min}$

h. Gradient: $0-2 \min (80 \% A, 20 \% B$ ) ramped to $20 \% A / 80 \% B$ at 8 min (hold for 2 $\mathrm{min}$ ), increase to $80 \% \mathrm{~A} / 20 \% \mathrm{~B}$ at $11 \mathrm{~min}$ (hold for $4 \mathrm{~min}$ ).

i. Column equilibration time between runs: 2 min

j. Column temperature: $30^{\circ} \mathrm{C}\left( \pm 5^{\circ} \mathrm{C}\right)$

k. Autosampler temperature: $4^{\circ} \mathrm{C}\left( \pm 2{ }^{\circ} \mathrm{C}\right)$ 
6. Summary of HPLC and MS characteristics:

\begin{tabular}{|c|c|c|c|c|c|c|c|}
\hline Analyte & $\begin{array}{c}\text { Parent ion } \\
(\mathrm{m} / \mathrm{z})\end{array}$ & $\begin{array}{c}\text { Product } \\
\text { Ions }(\mathrm{m} / \mathrm{z})\end{array}$ & Cone (V) & $\begin{array}{c}\text { Collision } \\
(\mathrm{eV})\end{array}$ & RT (min) & $\begin{array}{c}\text { MS } \\
\text { Channel }\end{array}$ & Conc \\
\hline \multirow[t]{2}{*}{$\mathrm{CBZ}$} & 237.08 & 194.2 & 25 & 20 & 9.02 & 2 & $E$ \\
\hline & & 192.2 & 25 & 20 & 9.02 & 1 & \\
\hline \multirow[t]{2}{*}{ OXC } & 253.10 & 236.28 & 15 & 10 & 8.28 & 6 & $\mathrm{D}$ \\
\hline & & 210.45 & 15 & 15 & 8.28 & 5 & \\
\hline \multirow[t]{2}{*}{ CBZ-epoxide } & 253.10 & 236.10 & 15 & 12 & 7.94 & 4 & $\mathrm{C}$ \\
\hline & & 180.20 & 15 & 15 & 7.97 & 5 & \\
\hline \multirow[t]{2}{*}{ CBZ-10OH } & 255.07 & 236.97 & 15 & 10 & 7.04 & 8 & B \\
\hline & & 194.07 & 15 & 15 & 7.04 & 7 & \\
\hline \multirow[t]{2}{*}{ CBZ-DiOH } & 271.10 & 236.09 & 15 & 15 & 5.35 & 9 & $A$ \\
\hline & & 253.39 & 15 & 15 & 5.35 & 10 & \\
\hline CBZ-D10 (IS) & 247.15 & 204.28 & 25 & 18 & 9.02 & 3 & $\mathrm{~F}$ \\
\hline
\end{tabular}

